No. 15

January 1914

\title{
MATHEMATICAL NOTES
}

A Review of Elementary Mathematics and Science

- PUBLISHED BY THE

\section{EDINBURGH}

MATHEMATICAL SOCIETY

EDITED BY

P. PINKERTON, M.Á., D.Sc.

\section{IEdínburgh :}

Printed for the Ediniurgh Mathematical Society by

LINDSAY \& CO., I7 BLACKFRIARS STREET.

I9I 4. 


\section{O N T ENTS.}

PAGE

Note on the Perpendicular Generators of a Hyperboloid

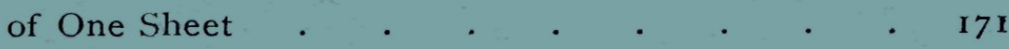

R. J. T. BELL, M.A., D.Sc.

Note on the Principal Axes of a Normal Section of a Cylinder which Envelopes an Ellipsoid . . . . 172

R. J. T. BELL, M.A., D.Sc.

A Construction by Ruler and Dividers . . . . 175

R. F. MUIRHEAD, B.A., D.Sc.

Elementary proof of the formula for $\alpha^{n}+\beta^{n}$ in terms of $\alpha+\beta$ and $\alpha \beta \quad$. $\quad . \quad . \quad . \quad . \quad . \quad . \quad . \quad . \quad 177$

John Dougall, M.A., D.Sc.

Arithmetical Solution of the Ages Problem . . $\ddots \quad 179$ John DOUGall, M.A., D.Sc.

The Equivalence of certain Simultaneous"Equations . $\quad$ I80 JOHN E. RIDLEY.

All contributions and communications referring to "MATHEMATICAL Notes" should be addressed to P. Pinkerton, High School, Glasgow.

The Annual Subscription to the Edinburgh Mathematical Society is 7s. 6d. for ordinary members, who receive copies of Mathematical Notes and also of the Proceedings of the Society. Any desiring to become members should apply to the Hon. Sec., P. Comrie, M.A., B.Sc., r9 Craighouse Terrace, Edinburgh. 